GRADIATION\&APPLICATIONS

ISSN 2466-4294 (online) | rad-journal.org

Vol. 2 | Issue 3 | pp. 204 - 209, 2017

doi: 10.21175/RadJ.2017.03.041

Original research paper

\title{
MORPHOMETRIC CHARACTERISTICS OF THE INFRAORBITAL FORAMEN ON VOLUME-RENDERED CT SCANS ${ }^{*}$
}

\author{
Marija Dakovic Bjelakovic ${ }^{* *}$, Jelena Popovic ${ }^{2}$, \\ Dragan Stojanov3, Tanja Dzopalic4, Jelena Ignjatovic5 \\ ${ }^{1}$ Department of Anatomy, Medical Faculty, University of Nis, Serbia \\ ${ }^{2}$ Department of Restorative Dentistry and Endodontics, Clinic of Dentistry, Medical Faculty, University of Nis, Serbia \\ 3 Center of Radiology, Clinical Center of Nis, Serbia \\ 4Department of Immunology, Medical Faculty, University of Nis, Serbia \\ 5Medical Faculty, University of Nis, Serbia
}

\begin{abstract}
In this study, we aimed to analyze the variability in the size and localization of infraorbital foramen (IOF) with respect to the surrounding anatomical bony landmarks using the three-dimensional computed tomography ( $3 D$ $C T)$ with the volume rendering and evaluate these morphometric parameters in relation to the gender and side. The cranial CT scans of 6 o living adult subjects, without any trauma or malformation of facial bones were included in the study. Data of the subjects were collected in the Center of Radiology, Clinical Center Nis, Serbia. Measurements included the transverse and vertical diameter of the IOF foramen, the distance from IOF to facial midline, the distance to lateral margin of the piriform aperture, the distance to infraorbital margin and the distance to maxillary alveolar border. All measurements were done bilaterally and performed with a digital coordinate caliper. Obtained results were statistically analyzed. Observation of 120 hemi-skulls revealed that the IOF was present in all of them. The mean transverse diameter of the IOF was $2.81 \pm 0.69 \mathrm{~mm}$ and the mean vertical diameter was $3.41 \pm 0.88 \mathrm{~mm}$. The IOF was located at an mean distance $26.17 \pm 1.69 \mathrm{~mm}$ from facial midline, $14.99 \pm 1.30 \mathrm{~mm}$ from the lateral margin of the piriform aperture, $9.06 \pm 1.01 \mathrm{~mm}$ below the IOM and $28.22 \pm 2.78 \mathrm{~mm}$ above the maxillary alveolar border. Statistically significant difference was found between males and females for the distance from IOF to PA ( $p<$ o.05). These morphometric characteristics may have important implications for the surgical and local anesthetic planning.
\end{abstract}

Key words: Infraorbital foramen; morphometry; computed tomography; volume rendering

\section{INTRODUCTION}

The infraorbital foramen (IOF) is an opening present bilaterally on the anterior surface of the maxillary body, just below the infraorbital border of the orbit. Forming the anterior end of the infraorbital canal (IOC), the IOF allows the passage of infraorbital neurovascular bundle into the facial region. [1, 2] The IOF is an important anatomical landmark and knowledge of its precise position is essential to avoid injuries of infraorbital vessels and nerve passing through this foramen [3].

The human infraorbital nerve is a purely sensory nerve that continued the maxillary nerve. It travels through the anterior part of the pterygopalatine fossa, and enters the orbit via the inferior orbital fissure. The nerve travels anteriorly through the infraorbital groove (IOG) and the IOC along the orbital floor, and emerges from the IOF onto the face $[1,3]$. Within the IOG and IOC, the infraorbital nerve provides alveolar branches that are responsible for the sensory innervation of the maxillary incisor, canine and premolar teeth and adjacent upper gingiva. When infraorbital nerve emerges from the IOF, it divides into distinct branches responsible for the sensory innervations of the skin of the lower eyelid, the skin of the vestibule of the nose and the skin of the anterior part of the cheek, upper limb and oral mucosa. The infraorbital artery, a branch of the maxillary artery, leaves the orbit and divides into branches to supply the infraorbital region $[1,2]$.

Clinically, the IOF represents a referent point in various surgical procedures and local anesthesia in dentistry, maxillofacial surgery, plastic surgery and ophthalmology. The IOF is also used as a pressure point to test the sensitivity of the infraorbital nerve. The identification of the IOF position is important for both diagnostic and clinical procedures $[4,5]$. The infraorbital nerve block (IONB) sometimes has an unpredictable effect and incomplete anesthesia because of the anatomical variation in individual patients. Injuries of infraorbital neurovascular bundle during surgical procedures cause

\footnotetext{
* The paper was presented at the Fifth International Conference on Radiation and Applications in Various Fields of Research (RAD 2017), Budva, Montenegro, 2017.

marijadb968@gmail.com
} 
bleeding and loss of sensation in the corresponding regions of the face [4]. Studies reporting the position of the IOF have been variable and their results were different. The positions of IOF vary among racial groups. Existing data concerning variations of the foramina related to the gender and side are still conflicting. Furthermore, large variations in measurements have been reported in the literature with regard to the distance between the IOF and other reference points on the face [6-12].

In this study, we aimed to analyze the variability in the size and position of IOF with respect to the surrounding anatomical bony landmarks on living subjects using the three-dimensional computed tomography (3D CT) with the volume rendering, and evaluate these morphometric variations in relation to the gender and side.

\section{MATERIAL AND METHODS}

The prospective study included CT scans of the head of 60 adult subjects (120 hemi-skulls), 36 men and 24 women, aged between 21 and 74 years, who did not have the previous medical history of any skull bone trauma, malformation and the surgery on the face. Data of the subjects were collected from the patients referred to the Center of Radiology, Clinical Center of Nis, Serbia, between April 2016 and November 2016 for MDCT examination of skull bones and cranial base. CT scans of heads acquired by a 64-slice multi-detector CT scanner (Aquillion 64, Toshiba, Japan), according to the standard protocol, with following parameters: $120 \mathrm{kVp}, 150 \mathrm{~mA}$, $0.5 \mathrm{~mm}$ thick axial slice and rotation time $0.5 \mathrm{~s}$. Scanning was performed from the vertex of the skull and extending inferiorly to below the mandible. Images were transferred to a computer workstation of the CT scanner. Threedimensional (3D) reconstructions of the skulls were conducted in the program Vital Image (version 4.1) with the bone window (100-300 Hounsfield units (HU).

Observation and measurements were performed on $3 \mathrm{D}$ volume-rendered images. Presence of IOF and its morphometric characteristics were recorded. Indirect measurements were done using the coordinate caliper of the CT scanner. Linear distances were determined by manually setting the measuring line between reference points that were previously identified and measuring the distances. All indirect measurements were made by the same researcher, two times for each of the linear parameters, at intervals of seven to ten days. The average values of two measurements were taken for the final statistical analysis. The facial midline (FML) was the critical starting line for morphometric analysis. The FML was determined by marking line between nasion, the point on the skull corresponding to the middle of the nasofrontal suture, to the anterior nasal spine and intermaxillary suture line. To estimate the size of the IOF, the maximum transverse diameter (IOF Td) and the maximum vertical diameter (IOF Vd) were measured (Figure 1). The maximum IOF Td was measured between two most distant points on the lateral and medial margin of the IOF, in a line perpendicular to the FML. The maximum IOF Vd was measured between two most distant points on the upper and lower margin of the IOF, in a line parallel to the FML. The horizontal position was analyzed by measurements of the distance from the medial margin of the IOF to the FML (IOF-FML) and the distance from the medial margin of the IOF to the lateral margin of the piriform aperture (IOF-PA), both in a line perpendicular to the FML. The vertical position was analyzed by measurements of the distance from the upper margin of the IOF to the inferior orbital rim (IOF-IOR) and the distance from the lower margin of the IOF to the maxillary alveolar border (IOF-MAB), both in a line parallel to the FML (Figure 2). All measurements were done bilaterally, and the data were compared between two genders and two sides for each measurement.

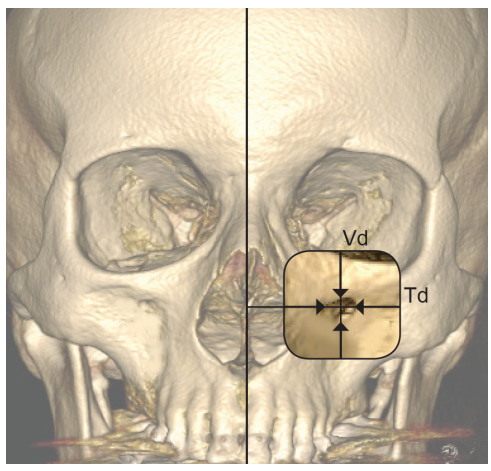

Figure 1. Method of measuring the dimensions of the infraorbital foramen: Td - transverse diameter; Vd - vertical diameter

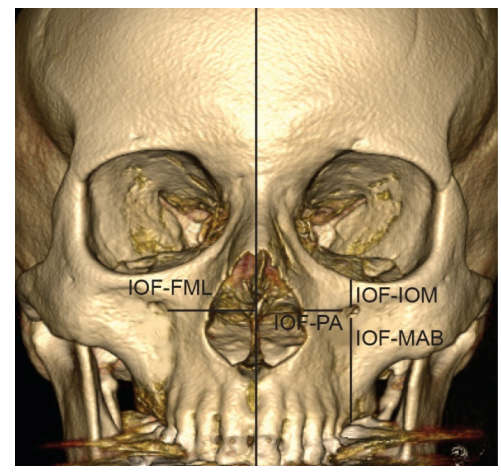

Figure 2. Measurements taken in the infraorbital region to estimate the position of the infraorbital foramen: IOFinfraorbital foramen; IOM-infraorbital margin; FML-facial midline; PA-piriform aperture; MAB-maxillary alveolar border

The obtained results were statistically analyzed using SPSS version 15.0. Descriptive statistics, the mean values, standard deviation (SD), minimum (Min) and maximum (Max) for each of the measurements were assessed. Student's $t$ test was performed to compare the morphometric variables in relation to the gender and side and Mann-Whitney U test was performed when data did not have normal distribution. The distributions of the continuous variables were assessed for normality by Shapiro-Wilk test. Because age has no normal distribution, correlations between age and other continuous variables were assessed by Spearman's rho correlation coefficients. Statistical differences were considered when the $p$ value was less than 0.05 . 
M. Dakovic Bjelakovic et al., Morphometric characteristics of the infraorbital foramen..., Rad. Applic., 2017, 2, 3, 204-209

\section{RESULTS}

Subjects included in the study comprised 36 men $(60.00 \%)$ and 24 women (40.00\%). The mean age of subjects was $58.56 \pm 14.83$ years (male, $59.27 \pm 12.16$; female, 53.67 \pm 20.67). There was no statistically significant difference between ages of genders $(p>0.05)$. Observation of 120 hemi-skulls revealed that the IOF was present in all of them. The data concerning the mean values of linear measurements of the IOF and comparison between right and left side are summarized in Table 1.

Table 1. Measurements of the infraorbital foramen related to side

\begin{tabular}{|l|rrrr|rrrrr|rrrr|r|r|}
\hline \multirow{2}{*}{ Measurement } & \multicolumn{4}{|c|}{ Total $(n=120)$} & \multicolumn{4}{c|}{ Right $(n=60)$} & \multicolumn{4}{c|}{ Left $(n=60)$} & $p$ \\
& Mean & SD & Min & Max & Mean & SD & Min & Max & Mean & SD & Min & Max & value \\
\hline IOF Td & 2.81 & O.69 & 1.40 & 4.70 & 2.83 & 0.92 & 1.50 & 4.70 & 2.78 & 0.88 & 1.40 & 4.60 & 0.388 \\
IOF Vd & 3.41 & 0.88 & 1.70 & 5.10 & 3.41 & 0.87 & 1.80 & 5.10 & 3.42 & 0.90 & 1.70 & 4.90 & 0.479 \\
IOF - IOM & 9.06 & 1.01 & 6.30 & 12.10 & 8.98 & 1.12 & 6.30 & 12.10 & 9.14 & 0.88 & 6.80 & 10.60 & 0.202 \\
IOF - FML & 26.17 & 1.69 & 21.60 & 29.70 & 26.35 & 1.84 & 23.00 & 29.70 & 25.98 & 1.50 & 21.60 & 28.90 & 0.139 \\
IOF - PA & 14.99 & 1.30 & 12.90 & 18.30 & 15.12 & 1.30 & 13.10 & 18.30 & 14.87 & 1.38 & 12.90 & 17.90 & 0.182 \\
IOF - MAB & 28.22 & 2.78 & 24.30 & 37.10 & 28.18 & 2.73 & 24.30 & 35.20 & 28.26 & 2.85 & 25.00 & 37.10 & 0.432 \\
\hline
\end{tabular}

All measurements are in mm. IOF - infraorbital foramen; Td - transversal diameter; Vd - vertical diameter; IOM - infraorbital margin; FML - facial -midline; PA - piriform aperture; MAB - maxillary alveolar border; ${ }^{*} \mathrm{p}<0.05 ;{ }^{* *} \mathrm{p}<0.01$.

Table 2. Measurements of the infraorbital foramen related to gender

\begin{tabular}{|c|c|c|c|c|c|c|c|c|c|}
\hline \multirow[t]{2}{*}{ Measurement } & \multicolumn{4}{|c|}{ Males $(n=72)$} & \multicolumn{4}{|c|}{ Females $(n=48)$} & \multirow[t]{2}{*}{ p value } \\
\hline & Mean & SD & Min & Max & Mean & SD & Min & Max & \\
\hline IOF Td & 2.86 & 0.88 & 1.60 & 4.70 & 2.72 & 0.92 & 1.40 & 4.70 & 0.202 \\
\hline IOF Vd & 3.43 & 0.89 & 1.80 & 5.10 & 3.38 & 0.87 & 1.70 & 4.80 & 0.384 \\
\hline IOF - IOM & 9.18 & 1.89 & 6.90 & 12.10 & 8.88 & 0.84 & 6.30 & 10.40 & 0.555 \\
\hline IOF - FML & 26.43 & 1.79 & 23.00 & 29.70 & 25.86 & 1.55 & 21.60 & 29.10 & 0.054 \\
\hline IOF - PA & $15 \cdot 38$ & 1.46 & 12.90 & 18.30 & 14.58 & 1.06 & 12.90 & 17.20 & $0.001^{*}$ \\
\hline IOF - MAB & 28.47 & 3.04 & 24.90 & 37.10 & 27.85 & 2.32 & 24.30 & 32.20 & 0.117 \\
\hline
\end{tabular}

All measurements are in $\mathrm{mm}$. IOF - infraorbital foramen; Td - transversal diameter; Vd - vertical diameter; IOM - infraorbital margin; FML - facial midline; PA - piriform aperture; MAB - maxillary alveolar border; *p<0.05.

Table 3. Measurements of the infraorbital foramen related to gender and side

\begin{tabular}{|l|r|c|c|c|}
\hline \multirow{2}{*}{ Measurement } & \multicolumn{2}{|c|}{ Male $(n=36)$} & \multicolumn{2}{c|}{ Female $(n=24)$} \\
\cline { 2 - 5 } & \multicolumn{1}{|c|}{ Right } & Left & Right & Left \\
\cline { 2 - 5 } & Mean \pm SD & Mean \pm SD & Mean \pm SD & Mean \pm SD \\
\hline IOF Td & $2.87 \pm 0.89$ & $2.86 \pm 0.87$ & $2.77 \pm 0.96$ & $2.67 \pm 0.90$ \\
IOF Vd & $3.41 \pm 0.89$ & $3.44 \pm 0.91$ & $3.39 \pm 0.87$ & $2.67 \pm 0.90$ \\
IOF - IOM & $9.11 \pm 1.27$ & $9.25 \pm 0.94$ & $8.80 \pm 0.90$ & $8.97 \pm 0.78$ \\
IOF - FML & $26.73 \pm 1.96$ & $26.12 \pm 1.59^{*}$ & $25.94 \pm 1.64$ & $25.83 \pm 1.49$ \\
IOF - PA & $15.52 \pm 1.41$ & $15.24 \pm 1.52$ & $14.68 \pm 1.03^{\dagger}$ & $14.47 \pm 1.09^{\ddagger}$ \\
IOF - MAB & $28.42 \pm 2.99$ & $28.51 \pm 3.28$ & $27.80 \pm 2.38$ & $27.90 \pm 2.31$ \\
\hline
\end{tabular}

All measurements are in $\mathrm{mm}$. IOF - infraorbital foramen; $\mathrm{Td}$ - transversal diameter;

Vd - vertical diameter; IOM - infraorbital margin; FML - facial midline; PA - piriform aperture; MAB - maxillary alveolar border;

${ }^{*} p<0.05$ vs male on the right side, ${ }^{\dagger} p<0.05$ vs male of the right side, ${ }^{*} p<0.05$ vs male of the left side

When gender and side factors were eliminated, the mean IOF Td and IOF Vd were $2.81 \pm 0.69 \mathrm{~mm}$ (minimum 1.40; maximum 4.70) and $3.41 \pm 0.88$ (minimum 1.70; maximum 5.10), respectively. The mean distances from the IOF to IOM, FML, PA, and MAB were $9.06 \pm 1.01 \mathrm{~mm}$ (minimum 6.30; maximum 12.10), $26.17 \pm 1.69 \mathrm{~mm}$ (minimum 21.60; maximum 29.70), $14.99 \pm 1.30 \mathrm{~mm}$ (minimum 12.90; maximum 18.30) and $28.22 \pm 2.78 \mathrm{~mm}$ (minimum 24.30; maximum 37.10), respectively. There were no statistically significant differences between right and left sides ( $p>0.05)$.

The comparison between the measurements of male and female is summarized in Table 2. All mean values were higher in male than in female skulls. A statistically significant difference was found between males and females for the distance IOF-PA $(\mathrm{p}<0.05)$. There was no statistically significant difference between the male and female in the other measurements $(\mathrm{p}>0.05)$.
The comparison between the measurements of right and left side of males and females is summarized in Table 3. We compared the values of linear measurements between the right and left side of the same gender and same side of the two genders. When comparing the values of linear measurements between the right and left side of the same gender, $t$ test showed a statistically significant difference between two sides in male for the distance IOF-FML $(p<0.05)$. When comparing the values of linear measurements between the same sides of the two genders, we found a statistically significant difference for the distance IOF-PA $(p<0.05)$. The mean values for this distance were significantly higher in male than in female on the right and left side. No significant difference was seen either when comparing between two sides of the same gender or the corresponding side of the two genders in other measurements $(p>0.05)$. 
The Spearman's correlation analysis was performed to define the relationship between aging and total values of linear measurements. The correlation coefficient showed no relation of age with all measurements (Table 4).

Table 4. Correlation of the aging with measurements

\begin{tabular}{|l|c|l|}
\hline & Coefficient & $p$ value \\
\hline IOF Td & 0.02 & 0.8963 \\
IOF Vd & -0.10 & 0.5789 \\
IOF - IOM & -0.14 & 0.4290 \\
IOF - FML & -0.15 & 0.4090 \\
IOF - PA & 0.03 & 0.8577 \\
IOF - MAB & 0.05 & 0.7808 \\
\hline
\end{tabular}

IOF - infraorbital foramen; Td - transversal diameter; Vd vertical diameter; IOM - infraorbital margin;

FML - facial midline; PA - piriform aperture; MAB - maxillary alveolar border; Significant differences, $p<0.05$

\section{Discussion}

Various anatomical studies have been conducted with the aim to describe anatomical variations of the exit point of the infraorbital nerve and vessels from the orbit [6-13]. For a number of years, the research on the morphometry of the IOF has been realized on cadaveric or dry skulls. The development of radiological techniques enabled the evaluation of anatomical structures on living subjects. During the last two decades, Computed Tomography (CT) techniques, which allow the investigation of fine anatomical details that are difficult to evaluate only by using axial reconstructions, were developed. Multidetector CT (MDCT) enables the visualization of very delicate bony structures due to its ability to produce an enormous amount of volumetric data in short time, high resolution and reliable multiplanar and three-dimensional (3D) reconstruction. Volume rendering (VR) enables the visualization of $\mathrm{CT}$ medical data by converting $3 \mathrm{D}$ dataset into a relevant two-dimensional (2D) image, providing users with a better understanding [14-16]. With the increasingly higher imaging capabilities of CT, skull foramina and other cranial structures are being seen as never before in living subjects [17].

Two different approaches to the study of IOF are available. The first one involves experimental procedures carried out on cadaveric and dry skulls [3-12]. The second one involves the evaluation of cranial structures by MDCT [13]. The findings of the previous studies that used cadaveric skulls and dry skulls showed the variability of size and position of IOF. The IOM is one of the most commonly used reference points. There was a wide range of values for the position of the IOF in relation to the IOM of the orbit, from $4 \mathrm{~mm}$ to over $10 \mathrm{~mm}$ [7-9], [11-12]. Our results were comparatively similar to that found in previous studies. The mean distance IOF-IOM in the present study was $8.98 \pm 1.12$ and $9.14 \pm 0.88 \mathrm{~mm}$ in the right and left side, and $9.18 \pm 1.89$ and $8.88 \pm 0.84 \mathrm{~mm}$ in male and female, respectively. There was no statistically significant difference between the genders and sides. However, Aziz et al. [6] have found a greater distance IOFIOM than that in the other study. This research conducted on 47 intact cadavers of both genders, 33 cadaveric heads of white persons and 11 cadaveric heads of the black persons. Results showed that the distance IOF-IOM was ranged from 2.5 to $15 \mathrm{~mm}$, with no significant differences between genders. The study of Gupta [10] conducted on 207
North-West Indian population has reported that the distance IOF - IOM was ranged from $3.2 \mathrm{~mm}$ to $13.2 \mathrm{~mm}$. Knowledge of distance IOF-IOM may be useful in identifying the position of the danger zone during surgical procedures. To apply an IONB, the surgeon needs to palpate the infraorbital margin to identify the IOF and then inject a local anesthetic [11]. However, palpating the IOM alone is not sufficient in locating the IOF in all cases. Knowing the relative distance of the IOF from other anatomical landmarks may help in defining the position of the infraorbital neurovascular bundle. In the previous study, the mean distances IOF-FML were reported as $26.45,26.95,28.5,25.26$, and $25.69 \mathrm{~mm}[6,8,10,11,12]$. Our results showed that the mean distances IOF-FML were $26.35 \pm 1.84 \mathrm{~mm}$ and $25.98 \pm 1.53 \mathrm{~mm}$ in the right and left side, and $26.43 \pm 1.79 \mathrm{~mm}$ and $25.86 \pm 1.55 \mathrm{~mm}$ in male and female, respectively. Furthermore, we also analyzed the distance IOF-PA. The mean distances IOFPA were $15.12 \pm 1.30 \mathrm{~mm}$ and $14.87 \pm 1.38 \mathrm{~mm}$ in the right and left side, and $15.38 \pm 1.46 \mathrm{~mm}$ and $14.58 \pm 1.06 \mathrm{~mm}$ in male and female, respectively. In the previous study, the average distance IOF-PA was reported as $14.72 \mathrm{~mm}$ and $15.19 \mathrm{~mm}[11,12]$. In this study, the mean distances IOF $\mathrm{MAB}$ were $28.18 \pm 2.73 \mathrm{~mm}$ and $28.26 \pm 2.85 \mathrm{~mm}$ in the right and left side, and $28.47 \pm 3.04 \mathrm{~mm}$ and $27.85 \pm 2.32 \mathrm{~mm}$ in male and female, respectively. Aggarwal et al. [12] found that the mean distance IOFMAB was about $28.5 \mathrm{~mm}$ on both sides. Although the range was from $20.50 \mathrm{~mm}$ to $34.82 \mathrm{~mm}$, in $75.0 \%$ of the skulls, the values were between 24 and $31 \mathrm{~mm}$. Our findings showed symmetry between sides. There was no significant difference between the genders and sides for the distance IOF-FML and for distance IOF-MAB. There was also no significant difference between the sides for distance IOF-PA, but there was significant difference $(p<0.05)$ between the genders for this measurement. All previous studies have shown similar results. The present findings suggest that gender should be taken into account when the IOF are to be located. However, when considering mean measurements between male and female skull, it was identified that all measurements were higher in men than in women. Sexual dimorphism is a morphological characteristic in human crania $[18,19]$.

The size of the IOF was also measured in the present study. Results of the present study showed that the mean IOF Td was $2.83 \pm 0.92 \mathrm{~mm}$ and $2.78 \pm 0.88 \mathrm{~mm}$ in the right and left side, and $2.86 \pm 0.88 \mathrm{~mm}$ and $2.72 \pm 0.92 \mathrm{~mm}$ in male and female, respectively. The mean IOF Vd was $3.41 \pm 0.87 \mathrm{~mm}$ and $3.42 \pm 0.90 \mathrm{~mm}$ in the right and left side, and $3.43 \pm 0.89 \mathrm{~mm}$ and $3.38 \pm 0.87 \mathrm{~mm}$ in male and female, respectively. We found that the mean size recorded in our study was comparable with that in the report by Gupta et al. [10], Chrcanovic et al. [11], Aggarwal et al. [12] and Berge and Bergman [17]. The study of Aziz et al. [6] showed that the average width of the IOF was about $4.5 \mathrm{~mm}$ in both genders, with a range of 1 to $7 \mathrm{~mm}$. The diameter of the IOF increases with the thickness of the infraorbital nerve and vessels. If the diameter of the IOF is small, it may be difficult to approach the infraorbital nerve [20].

In this study, the IOF of living subjects were analyzed. We made some interpretations of our CT measurements comparing with the previous cadaveric and dry skull studies. However, such comparison is limited, considering different methodological approaches. The correct data comparison can be made only with a study with the same research topic and the same methodology. As far as we 
know, there's only one similar study conducted on living subjects. Hwang et al. [13] examined variations of IOG, IOC and IOF on 100 living subjects using MDCT and evaluated the obtained results according to the gender and side. Their results showed that the mean distances IOFIOM and IOF-FML were $9.6 \pm 1.7 \mathrm{~mm}$ and $26.5 \pm 1.9 \mathrm{~mm}$, respectively. There was a significant difference between genders only in the distance IOF-FML. We concluded that our findings are generally similar to the previous reports. However, our study is more comprehensive since we used more morphometric parameters for the evaluation of the size and position of the IOF. We determined the position of the IOF according to the IOM, FML, PA and MAB. The data could be useful to surgeons considering that following anatomical landmarks and extreme caution in surgical interventions may lead to the prevention of iatrogenic injuries of the infraorbital neurovascular bundle.

The knowledge of the variability of the IOF enables the determination of the position of infraorbital neurovascular bundles with the aim of increasing successful interventions and avoiding sequel $[11,21]$. Precise and effective analgesia can be achieved only if the surgeon is aware of the most frequent position of the exit of regional nerve. The IONB is an effective method of anesthesia for repairing facial lacerations of the upper lip, nose, and medial cheek, as well as in the chronic pain settings $[4,5,22]$. Both extraoral and intraoral approaches to blocking the infraorbital nerve have been described. The extraoral or percutaneous technique involves a direct needle puncture through the skin across the site of the foramen $[5,22]$. Although it would be important to palpate and identify the IOF under overlying soft tissue, the knowledge of the position of the IOF and its relationship with the surrounding landmarks such as IOM or FML is useful for a safe regional block anesthesia. Intraoral approach is enabled by elevating the upper lip and passing the needle through the junction of the oral mucosa at the superior aspect of the oral vestibule. This technique is, except for the treatment of wounds infraorbital region, more commonly used for repairing the maxillary incisor teeth. The intraoral techniques employ a longer passage of the needle through the mouth using the canine tooth as an anatomical landmark and the canine fossa as an entry point $[2,22]$. Knowledge of the vertical distance of the IOF from the MAB can help to identify the exit point of the infraorbital nerve. Exact position of the IOF could be detected by a conventional radiological technique before surgery [21]. When these procedures are not available or are contraindicated, knowing the anatomical landmarks is important for the success rate of surgical repair and for the regional block anesthesia.

\section{CONCLUSION}

The present study provides information concerning the morphometric characteristics of the exit point of the infraorbital neurovascular bundle in southeast Serbian population. 3D-CT with the VR enables excellent visualization of bone structures of the face. The results are of direct relevance to assist anthropologists and forensic scientists in the localization and characterization of the infraorbital structures. The data on variations in the size and the position of the IOF would be useful to the surgeons, specially the maxillofacial surgeons, during any surgeries involving the infraorbital region, as well as anticipating the exact position infraorbital nerve for regional nerve block.

Acknowledgement: Contract grant sponsor: Ministry of Science and Technological Development of Republic of Serbia; contract grant number: 175092.

\section{REFERENCES}

1. Gray's anatomy, P. L. Williams, R. Warwick, M. Dyson, L. H. Bannister, Eds., 37th ed., Edinburg, UK: Churchil Livingstone, 1989.

2. K. L. Moore and A.F. Dalley, Clinically oriented anatomy, 5th ed., Philadelphia (PA), USA: Lippincott Williams \& Wilkins, 2006.

3. C. T. Mcqueen, D. C. Diruggiero, J. P. Campbell and W. W. Shockly, "Orbital osteology: A study of the surgical lendmarks," Laryngoscope, vol. 105, no. 8, pp. $783-788$, Aug. 1995.

DOI: 10.1288/00005537-199508000-00003 PMid: 7630287

4. G. A. Salam, "Regional anesthesia for office procedures: part I. Head and neck surgeries," Am. Fam. Physician, vol. 69, no. 3, pp. 585 - 590, Feb. 2004.

Retrieved from:

http://www.aafp.org/afp/2004/0201/p585.pdf Retrieved on: Feb. 12, 2017

5. D. J. Kleier, D. K. Deeg and R. C. Averbach, "The extraoral approach to the infraorbital nerve block," J. Am. Dent. Assoc., vol. 107, no. 5, pp. 758 - 760, Nov. 1983.

Retrieved from: http://jada.ada.org/article/SoOO2$\underline{8177 \% 2883 \% 2975018-X / p d f}$ Retrieved on: Feb. 12, 2017

6. S. R. Aziz, J. M. Marchena and A. Puran, "Anatomic characteristics of the infraorbital foramen: a cadaveric study," J. Oral. Maxillofac. Surg., vol. 58, no. 9, pp. 992 - 996, Sep. 2000.

DOI: $10.1053 /$ joms.2000.8742

PMid: 10981979

7. M. Kazkayasi, A. Ergin, M. Ersoy, O. Bengi, I. Tekdemir and A. Elhan, "Certain anatomical relations and the precise morphometry of the infraorbital foramen - canal and groove: an anatomical and cephalometric study," Laryngoscope, vol. 111, no. 4, pp. 609 - 614, Apr. 2001.

DOI: 10.1097/00005537-200104000-00010 PMid: 11359128

8. B. Cutright, N. Quillopa and W. Schubert, "An antropometric analysis of the key foramina for maxillofacial surgery," J. Oral. Maxillofac. Surg., vol. 61, no. 3, pp. 354 - 357, Mar. 2003.

DOI: $10.1053 /$ joms.2003.50070

PMid: 12618976

9. S. Agthong, T. Huanmanop and V. Chentanez, "Anatomical variations of the supraorbital, infraorbital and mental foramina related to the gender and side," $J$. Oral. Maxillofac. Surg., vol. 63, no. 6, pp. 800 - 804, Jun. 2005. DOI: $10.1016 /$ j.joms.2005.02.016 PMid: 15944977

10. T. Gupta, "Localization of the important facial foramina encountered in maxillo-facial surgery," Clin. Anat., vol. 21, no. 7, pp. $633-644$, Oct. 2008.

DOI: $10.1002 /$ ca.20688 PMid: 18773483

11. B. R. Chrcanovic, M. H. Nogueira, G. Abreu and A. L. N. Custodio, "A morphometric analysis of the supraorbital and infraorbital foramina relative to surgical landmarcs," Surg. Radiol. Anat., vol. 33, no. 4, pp. 329 335, May 2011.

DOI: 10.1007/soo276-010-0698-1

PMid: 20625730 
12. A. Aggarwal et al., "Anatomical study of the infraorbital foramen: a basis for successful infraorbital nerve block," Clin. Anat., vol. 28, no. 6, pp. 753 - 760, Sep. 2015.

DOI: $10.1002 / \mathrm{ca} .22558$

PMid: 26119635

13. S. H. Hwang et al., "Morphometric analysis of the infraorbital groove, canal, and foramen on threedimensional reconstruction of computed tomography scans," Surg. Radiol. Anat., vol. 35, no. 7, pp. 565 - 571, Sep. 2013.

DOI: $10.1007 /$ s00276-013-1077-5

PMid: 23404562

14. H. Jung et al., "Quantitative analysis of threedimensional rendered imaging of the human skull acquired from multi-detector row computed tomography,” J. Digit. Imaging, vol. 15, no. 4, pp. 232 239, Dec. 2002.

DOI: $10.1007 / \mathrm{s} 10278-002-0031-6$

PMid: 12532254

PMCid: PMC3611620

15. S. Perandini, N. Faccioli, A. Zaccarella, T. Re and R. P. Mucelli, "The diagnostic contribution of CT volumetric rendering techniques in routine practice," Indian. J. Radiol. Imaging, vol. 20, no. 2, pp. 92 - 97, May 2010.

DOI: $10.4103 / 0971-3026.63043$

PMid: 20607017

PMCid: PMC2890933

16. B. S. Kuszyk, D. G. Heath, D. F. Bliss and E. K. Fishman, "Skeletal 3-D CT: advantages of volume rendering over surface rendering," Skeletal. Radiol., vol. 25, no. 3, pp. 207 - 214, Apr. 1996.

DOI: $10.1007 /$ s002560050066

PMid: 8741053
17. J. K. Berge and R. A. Bergman, "Variations in size and in symmetry of foramina of the human skull," Clin. Anat., vol. 14, no. 6, pp. 406 - 413, Nov. 2001. DOI: $10.1002 /$ ca.1075

PMid: 11754234

18. A. B. Berry, "Factors affecting the incidence of non-metrical skeletal variants," J. Anat., vol. 120, no. 3, pp. $519-535$, Dec. 1975 .

Retrieved from:

https://www.ncbi.nlm.nih.gov/pmc/articles/PMC12316 93/pdf/janato0377-0100.pdf Retrieved on: Feb. 12, 2017

19. A. Carolineberry and R. J. Berry, "Epygenetic variations in the human cranium," J. Anat., vol. 101, no. 2, pp. 361 - 379, Apr. 1967.

Retrieved from:

https://www.ncbi.nlm.nih.gov/pmc/articles/PMC1270 890/pdf/janato0410-0155.pdf Retrieved on: Feb. 12, 2017

20. T. J. Leo, M. Cassell and R. A. Bergman, "Variation in human infraorbital nerve, canal and foramen," Ann. Anat., vol. 177, no. 1, pp. 93 - 95, Jan. 1995.

DOI: 10.1016/So940-9602(11)80139-1

21. M. Kazkayasi, A. Ergin, M. Ersoy, I. Tekdemir and A. Elhan, "Microscopic anatomy of the infraorbital canal, nerve, and foramen," Otolaryngol. Head. Neck. Surg., vol. 129, no. 6, pp. 629-697, Dec. 2003. DOI: 10.1016/So194-5998(03)01575-4

22. M. L. Lynch, S. A. Syverud, R. A. Schwab, J. M. Jenkins and R. Edlich, "Comparison of intraoral and percutaneous approaches for infraorbital nerve block," Acad. Emerg. Med.,_vol. 1, no. 6, pp. 514 - 519, Nov-Dec. 1994.

Retrieved from:

http://onlinelibrary.wiley.com/doi/10.1111/j.15532712.1994.tb02543.x/pdf

Retrieved on: Feb. 12, 2017 